\title{
Growth and characterization of nonlinear optical single crystals: bis(cyclohexylammonium) terephthalate and cyclohexylammonium para-methoxy benzoate
}

\author{
P SATHYA, M ANANTHARAJA, N ELAVARASU and R GOPALAKRISHNAN* \\ Crystal Research Lab, Department of Physics, Anna University, Chennai 600 025, India
}

MS received 12 November 2014; accepted 30 April 2015

\begin{abstract}
Bis(cyclohexylammonium) terephthalate (BCT) and cyclohexylammonium 4-methoxy benzoate (C4MB) single crystals were successfully grown by the slow evaporation solution growth technique. The harvested crystals were subjected to single-crystal $X$-ray diffraction, spectral, optical, thermal and mechanical studies in order to evaluate physiochemical properties. The Kurtz and Perry technique for second harmonic generation (SHG) study revealed that the powdered materials of BCT and C4MB exhibit SHG efficiency 0.2 times less and 1.3 times greater than that of standard reference material potassium dihydrogen phosphate. C4MB crystal exhibits high efficiency than BCT, because of methoxy group substituted in the para position of phenyl ring. With high SHG efficiency and thermal stability para substituted C4MB crystal will be a potential candidate for optical device fabrication.
\end{abstract}

Keywords. Organic compound; growth from solution; characterization; nonlinear optical materials.

\section{Introduction}

Organic nonlinear optical (NLO) materials have attracted much attention due to their potential applications in telecommunication, optical switching, optical frequency conversion, $\mathrm{THz}$ generation, electro-optical and integrated optics. $^{1,2}$ In recent times, polar aromatic organic molecules have received great attention for NLO applications. However, NLO properties of several inorganic crystals such as $\mathrm{LiNbO}_{3}, \mathrm{GaP}$ have been widely investigated. The NLO property in organic molecules mainly associates with polar functional group and large molecular hyperpolarizability, which are facilitated to electron delocalization. In addition to that the molecules should form noncentrosymmetrical crystal structure that provides nonvanishing second-order nonlinear coefficients. ${ }^{3-5}$ By this way, hydrogen bonding, steric substitution and chirality molecules have also been proposed to crystallize into a noncentrosymmetric structure. ${ }^{6}$

Donor/acceptor benzene derivatives are demonstrated to produce high molecular nonlinearity. Till date many organic donor $-\pi$-acceptor $(\mathrm{D}-\pi-\mathrm{A})$ type compounds have been studied theoretically and also experimentally. Cyclohexylammonium 4-methoxy benzoate (C4MB) crystal is $\mathrm{D}-\pi-\mathrm{A}$ type in organic molecules and expected to be a promising candidate for second harmonic generation (SHG). ${ }^{7,8}$ The cyclohexylamine is new to crystal

*Author for correspondence (krgkrishnan@yahoo.com, krgkrishnan@annauniv.edu) growth researchers and an interesting base material for different organic systems. It is a strong base and can easily react with all acids to form salts. Consequently the nitrogen atom in cyclohexylamine is extremely reactive on the organic compounds containing acid anhydrides. Hence, cyclohexylamine is selected to react with two different acids, i.e., terephthalic acid and para-methoxy benzoic acid. Both acids are having aromatic molecules and directional hydrogen bonds. Further, the numbers of carboxylic groups are placed at different positions of aromatic ring. . Here, methoxy (-OMe) group is substituted in a para position of phenyl ring which predicts an electron donating system and plays an important role in the crystal structure and SHG activity of the title compound. ${ }^{10-12}$

The present investigation gives the detailed results of growth, structural, optical, mechanical, thermal and NLO behaviour of the title compounds. It is interesting to study the new base-acid complex, bis(cyclohexylammonium) terephthalate (BCT) and cyclohexylammonium paramethoxy benzoate, which have been grown by the slow evaporation solution technique.

\section{Experimental}

\subsection{Synthesis and crystal growth of BCT and C4MB}

Cyclohexylamine, terephthalic acid and para-methoxy benzoic acid reagents were the starting materials used to synthesise the title compounds. BCT crystal was grown by 
reacting terephthalic acid and cyclohexylamine in the ratio of $1: 2$ in water solvent. Two protons are transferred from terephthalic acid to cyclohexylamine resulting in the formation of ions as depicted in figure 1. Similarly, $\mathrm{C} 4 \mathrm{MB}$ was grown by mixing the cyclohexylamine and para-methoxy benzoic acid in equimolar ratio. Here a mixed solvent of water and ethanol were used to grow good quality crystals. The possible growth mechanism of $\mathrm{C} 4 \mathrm{MB}$ is depicted in figure 2 . The filtered solution was kept at $32^{\circ} \mathrm{C}$ and allowed for slow evaporation of solvents. Good quality transparent single crystals were harvested after a period of 4 weeks followed by recrystal- lization process. The grown crystals are shown in figure 3 .

\subsection{Characterization techniques}

Crystal structure was confirmed by single-crystal X-ray diffraction (XRD) using ENRAF(BRUKER) NONIUS CAD 4 Kappa APEX II X-ray diffractometer equipped with MoK $\alpha$ radiation $(\lambda=0.71073 \AA)$. The Fourier transform infrared (FT-IR) spectrum was recorded in the range $400-4000 \mathrm{~cm}^{-1}$ using $\mathrm{KBr}$ pellet on Bruker Alpha spectrometer. The number of protons and carbons present in<smiles>NC1CCCCC1</smiles><smiles>O=C(O)c1ccc(C(=O)O)cc1</smiles>

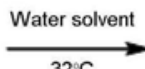<smiles>NC1CC2CCCC1C2</smiles><smiles>O=C([O-])c1ccc(C(=O)[O-])cc1</smiles>

Figure 1. Reaction scheme of BCT.<smiles>COc1ccc(C(=O)O)cc1</smiles><smiles>[NH3+]C1CCCCC1</smiles><smiles>COc1ccc(C(=O)[O-])cc1</smiles>

Figure 2. Reaction scheme of C4MB.
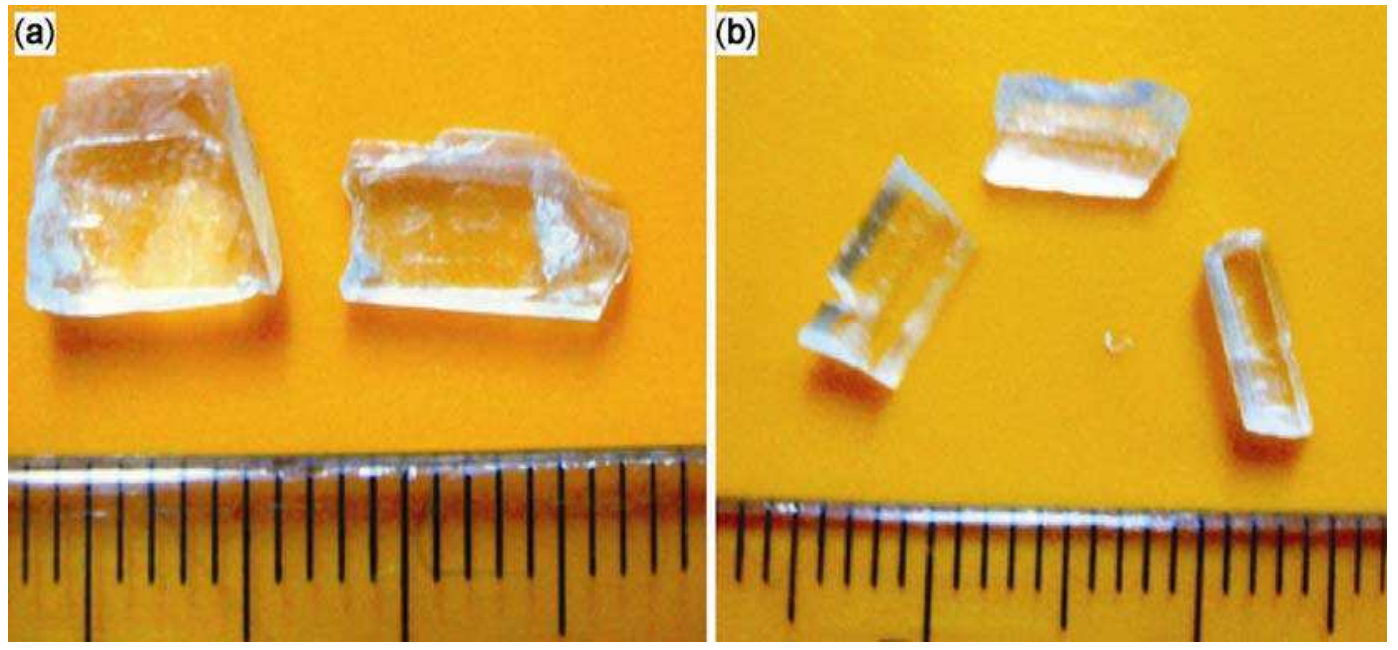

Figure 3. Single crystals of bis(cyclohexylammonium) terephthalate (crystal a) and cyclohexylammonium para-methoxy benzoate (crystal b). 
the compounds were confirmed by FT-NMR $500 \mathrm{mHz}$ analysis. Optical absorption spectral analysis was carried out using CARY 5E UV-vis spectrophotometer in the range of $200-800 \mathrm{~nm}$. The fluorescence property of crystal was obtained using Fluorescence Spectrometer Perkin Elmer LS 45. The microhardness was tested by MATSUZAWA microhardness tester fitted with Vickers diamond pyramidal indenter attached to an incident light microscope. The thermogravimetric (TG) and differential thermal analyses (DTA) were made by NETZSCH STA $409^{\circ} \mathrm{C}$ analyser in the temperature range between 25 and $1000^{\circ} \mathrm{C}$ under nitrogen atmosphere with a heating rate of $10 \mathrm{~K} \mathrm{~min}^{-1}$. The Kurtz and Perry powder technique was performed in order to obtain the SHG efficiency.

\section{Results and discussion}

\subsection{Single-crystal XRD analysis}

From single-crystal XRD data, it can be observed that $\mathrm{BCT}$ and $\mathrm{C} 4 \mathrm{MB}$ crystals belong to monoclinic system with noncentrosymmetric space group (table 1). In the title compounds, cations and anions are linked by $\mathrm{N}-\mathrm{H}$... O hydrogen bonds between the $\mathrm{H}$ atoms of the ammonium group and the $\mathrm{O}$ atoms of the carboxylate group, which also make a great contribution to the stability of the crystal structure. ${ }^{13,14}$ Both space groups of the title crystals reveal no inversion symmetry (noncentrosymmetry), hence they may exhibit SHG.

\subsection{FT-IR analysis}

FT-IR is a non-destructive microanalytical spectroscopy technique that involves understanding of molecular vibration and chemical bonding of the title compound. The beam of infrared radiation is passed through compounds. Molecular bonds and group of bonds vibrate by absorbing infrared energy at particular wavelengths. ${ }^{15}$ BCT and C4MB are subjected to FT-IR studies. The resulting FTIR spectrum is shown in figure 4 . The results of BCT and
C4MB are interpreted and presented in table 2. Paramethoxy group has been clearly observed at $847 \mathrm{~cm}^{-1}$ in the FT-IR spectrum of C4MB. In the C4MB crystal, the $\mathrm{C}=\mathrm{O}$ stretching vibration occurs at $1741 \mathrm{~cm}^{-1}$ owing to the intramolecular hydrogen bonding and the presence of strong electronegative atom causing large degree of molecular, $\pi$-electron delocalization and redistribution of electrons, which weakens $\mathrm{C}=\mathrm{O}$ bond. ${ }^{16}$ Observed FT-IR spectra strongly confirm BCT and para-substituted C4MB crystals.

\subsection{Nuclear magnetic resonance (NMR) studies}

To confirm the molecular structure of BCT and C4MB crystal, the ${ }^{1} \mathrm{H}$ and ${ }^{13} \mathrm{C}$ NMR spectra were recorded using deuterated methanol as a solvent. BCT and $\mathrm{C} 4 \mathrm{MB}$ crystals were crushed and dissolved in $\mathrm{CD}_{3} \mathrm{OD}$. Figure $5 \mathrm{a}$ and $b$, respectively, shows the ${ }^{1} \mathrm{H}$ NMR spectrum of BCT and C4MB. The multiplet peaks at $1.8,1.4 \mathrm{ppm}$ for BCT and $1.7,1.4 \mathrm{ppm}$ for $\mathrm{C} 4 \mathrm{MB}$ are due to cyclic aliphatic proton in the cyclohexylamine. The sharp intense peak at $3.8 \mathrm{ppm}$ is due to the protons in the methyl substituted benzoate. A sharp singlet peak at $5.1 \mathrm{ppm}$ in both compounds is assigned for amine group $\left(\mathrm{NH}_{3}\right)$. Both the materials show the aromatic proton peak at $7.9 \mathrm{ppm}$ (BCT) and 8.1, 7.1 ppm (C4MB). The strong intense peak at $3.8 \mathrm{ppm}$ corresponds to the methoxy (-OMe) proton that either has relatively low electron density around it (electron donor groups) or that is attached to a carbon atom taking part in a $\pi$-bond.

The ${ }^{13} \mathrm{C}$ NMR spectra of BCT and C4MB are shown in figure $5 \mathrm{c}$ and $\mathrm{d}$, respectively. The peaks at 24.52 and $30.65 \mathrm{ppm}$ for both BCT and C4MB are due to aliphatic carbon. The resonance peak at $50.06 \mathrm{ppm}$ in both the crystals is attributed to $\mathrm{C}$ atom in cyclohexane. The peak at $\delta=54.37 \mathrm{ppm}$ for $\mathrm{C} 4 \mathrm{MB}$ is mainly due to the methyl group. The NMR signals at $128.26 \mathrm{ppm}$ (BCT) and 130.71, $112.53 \mathrm{ppm}$ (C4MB) correspond to benzene ring carbon atoms. The resonance at $173.6 \mathrm{ppm}$ in both compounds is due to carbonyl atom in acid functional group. Table 3 shows the ${ }^{1} \mathrm{H}$ and ${ }^{13} \mathrm{C}$ NMR spectra result of BCT and C4MB.

Table 1. Cell parameter values of BCT and C4MB.

\begin{tabular}{|c|c|c|c|c|}
\hline \multirow[b]{2}{*}{ Crystal data } & \multicolumn{2}{|l|}{$\mathrm{BCT}$} & \multicolumn{2}{|l|}{$\mathrm{C} 4 \mathrm{MB}$} \\
\hline & Obtained values & Reported values & Obtained values & Reported values \\
\hline System & Monoclinic & Monoclinic & Monoclinic & Monoclinic \\
\hline Space group & $\mathrm{Cc}$ & $\mathrm{Cc}$ & $\mathrm{P} 2_{1}$ & $\mathrm{P} 2_{1}$ \\
\hline$a(\AA)$ & $11.5839(3)$ & $11.572(2)$ & $8.91(18) \AA$ & $8.9076(18)$ \\
\hline$b(\AA)$ & $22.8008(5)$ & $22.820(5)$ & $6.62(12) \AA$ & $6.6025(13)$ \\
\hline$c(\AA)$ & $8.5272(16)$ & $8.5426(17)$ & $11.78(2) \AA$ & $11.778(2)$ \\
\hline$\alpha, \beta, \gamma$ & $\alpha, \gamma=90^{\circ}, \beta=117.0881^{\circ}(3)$ & $\beta=117.03^{\circ}(3)$ & $\alpha, \gamma=90^{\circ}, \beta=102.70(4)^{\circ}$ & $\beta=102.85(3)^{\circ}$ \\
\hline$V$ & $2005.1587 \AA^{3}$ & $2009.5(7) \AA^{3}$ & $678 \AA^{3}$ & $V=675.3(2) \AA^{3}$ \\
\hline
\end{tabular}


Table 2. Assignment of vibrational frequencies of BCT and C4MB.

\begin{tabular}{lll}
\hline $\begin{array}{l}\text { BCT } \\
\text { wavenumber }\left(\mathrm{cm}^{-1}\right)\end{array}$ & $\begin{array}{c}c \\
\mathrm{C} 4 \mathrm{MB} \\
\text { wavenumber }\left(\mathrm{cm}^{-1}\right)\end{array}$ & \multicolumn{1}{c}{ Assignment } \\
\hline 3445 & $3900,3851,3741$ & $\mathrm{NH}_{3}$ asymmetrical stretching \\
2938,2854 & 2937,2853 & $\mathrm{C}-\mathrm{H}$ stretching \\
2191 & 2219 & $\mathrm{C} \equiv \mathrm{N}$ stretching \\
- & 1741 & $\mathrm{C}=\mathrm{O}$ stretching \\
1634 & 1639 & $\mathrm{C}=\mathrm{C}$ stretching \\
1578 & 1521,1587 & Asymmetry COO ${ }^{-}$stretching \\
1443 & 1449 & $\mathrm{C}-\mathrm{C}$ stretching in aromatic ring \\
1367,1080 & 1372,1098 & $\mathrm{C}-\mathrm{N}$ stretching in aromatic ring \\
- & 1310 & $\mathrm{C}-\mathrm{OCH}$ stretching \\
1135 & 1161 & $\mathrm{C}-\mathrm{C}-\mathrm{O}$ stretching \\
1024 & 1028 & $\mathrm{C}-\mathrm{H}$ in plan bending \\
& 847 & $\mathrm{C}-\mathrm{H}$ out of plan bending, para substituted \\
746 & 781 & $\mathrm{NH}{ }_{3}^{+}$rocking \\
- & 611 & $\mathrm{C}-\mathrm{C}-\mathrm{O}$ rocking \\
- & 533 & $\mathrm{C}-\mathrm{OCH} \mathrm{H}_{3}$ out of plan bending \\
\hline
\end{tabular}

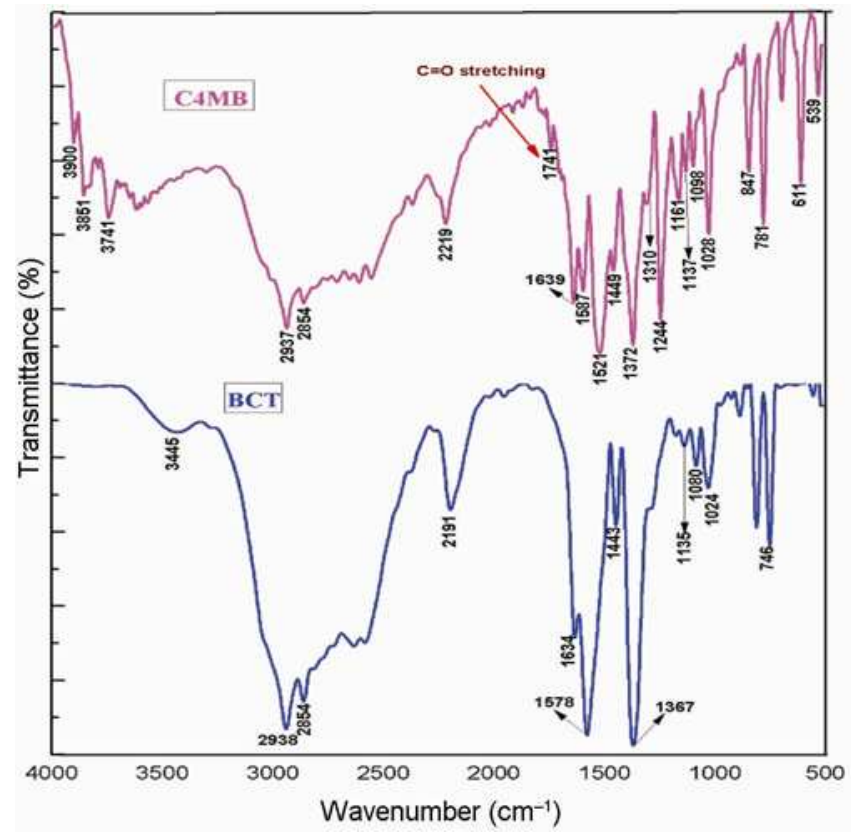

Figure 4. FT-IR spectrum of $\mathrm{BCT}$ and $\mathrm{C} 4 \mathrm{MB}$.

\subsection{UV-visible absorption spectrum}

In general UV-visible absorption in organic materials involves promotion of electrons between $\sigma$ and $\pi$ orbital from ground state to higher energy states. ${ }^{17}$ Optical window width is an important property for NLO materials. Hence UV-visible absorption range of the title compound is necessary for optical applications. The BCT and C4MB crystals were well polished and subjected to UVvisible spectral analysis in the wavelength range 200$800 \mathrm{~nm}$. Figure $6 \mathrm{a}$ and $\mathrm{c}$ shows the absorption spectrum of BCT and C4MB crystals. The cutoff wavelength was found to be $295 \mathrm{~nm}$ for BCT and $325 \mathrm{~nm}$ for C4MB owing to strong $\pi \rightarrow \pi^{*}$ electronic transition. ${ }^{18}$ This band may be occurring in the aromatic ring $\mathrm{C}=\mathrm{O}$ group. ${ }^{19}$ The absence of energy absorption in the UV-visible absorption spectrum in entire visible region indicates the title crystals are desirable for NLO applications.

The optical absorption coefficient $(\alpha)$ of a crystal with different thicknesses can be calculated using the relation

$$
\alpha=\frac{1}{d_{2}-d_{1}} \times \ln \left(\frac{T_{1}}{T_{2}}\right),
$$

where $d_{1}$ and $d_{2}$ are the two different thicknesses of the crystals and $T_{1}$ and $T_{2}$ are the transmittance of the crystal thickness $d_{1}$ and $d_{2}$, respectively.

The transmittance spectra of BCT crystals of thickness 3 and $2 \mathrm{~mm}$ were recorded, whereas for C4MB crystal, 3 and $1 \mathrm{~mm}$ thicknesses were used.

The optical bandgap energy is calculated from absorption spectra using the relation

$$
\alpha h v=A\left(h v-E_{\mathrm{g}}\right)^{n},
$$

where exponent $n=1 / 2$ for direct allowed transition, $n=3 / 2$ for direct forbidden transition, $n=2$ for indirect allowed transition and for indirect forbidden transition $n=3$; $A$ is a constant, $E_{\mathrm{g}}$ is the optical bandgap, $h v$ the photon energy $(v=c / \lambda)$. The optical bandgaps of the BCT and C4MB crystals were estimated by plotting $(\alpha h v)^{1 / 2}$ with $h v$ as shown in figure $6 \mathrm{~b}$ and $\mathrm{d}$. The indirect optical bandgap of grown BCT and C4MB crystals are found to be 3.8 and $3.7 \mathrm{eV}$, respectively. The values are obtained by extrapolating linear part of the absorption edge to the energy axis.

\subsection{Fluorescence studies}

Fluorescence property is used to determine the crystalline quality as well as its exciton fine structure. The 
(a)

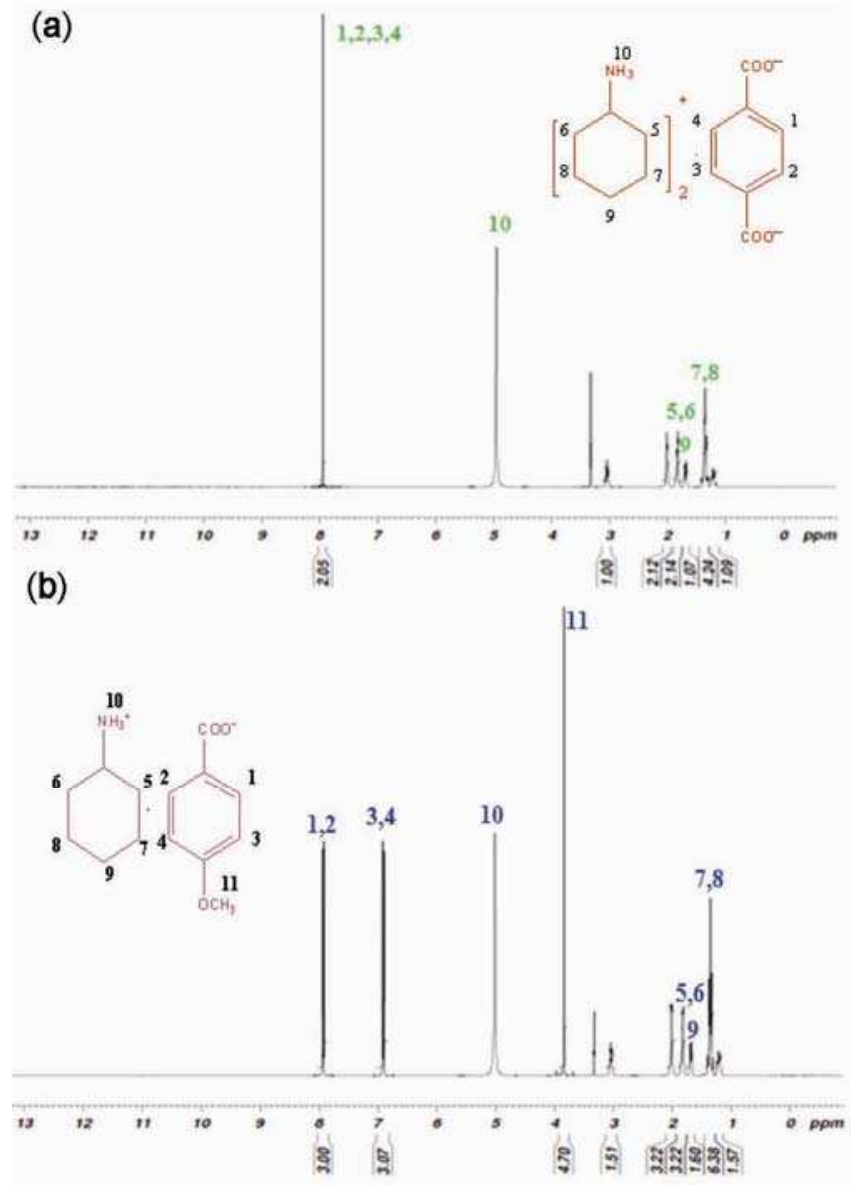

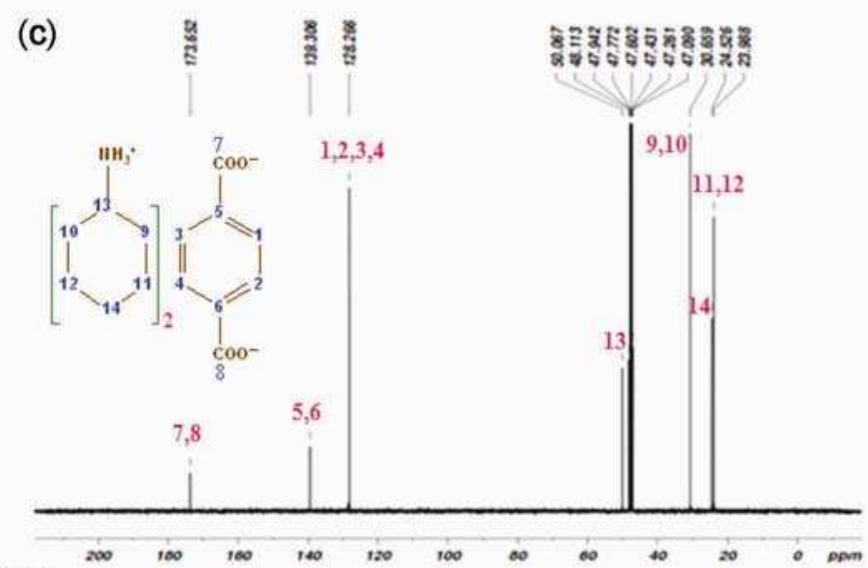

(d)

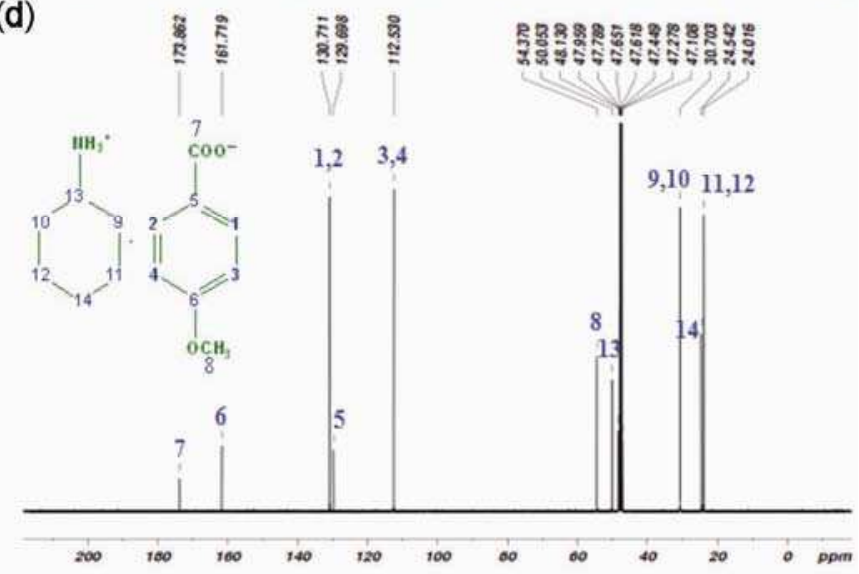

Figure 5. ${ }^{1} \mathrm{H}$ NMR spectrum of (a) BCT and (b) C4MB; and ${ }^{13} \mathrm{C}$ NMR spectrum of (c) BCT and (d) C4MB.

Table 3. ${ }^{1} \mathrm{H}$ and ${ }^{13} \mathrm{C}$ NMR spectra result of BCT and C4MB.

\begin{tabular}{|c|c|c|c|}
\hline Spectrum & $\begin{array}{c}\text { BCT } \\
\text { Signal at } \delta \text { ppm }\end{array}$ & $\begin{array}{c}\text { C4MB } \\
\text { Signal at } \delta \text { ppm }\end{array}$ & Group identification \\
\hline${ }^{1} \mathrm{H}$ & $\begin{array}{l}7.9 \\
5.1 \\
3.2 \\
2 \\
1.8,1.4,1.2\end{array}$ & $\begin{array}{l}8.1,7.1 \\
5.1 \\
3.3 \\
2 \\
1.7,1.4,1.2 \\
3.8\end{array}$ & $\begin{array}{l}\text { Benzene ring }(\mathrm{C}-\mathrm{H}, \mathrm{C}-\mathrm{H}, \mathrm{C}-\mathrm{H}, \mathrm{C}-\mathrm{H}) \text { in acid }(\mathrm{s}) \\
\text { Amine }\left(\mathrm{NH}_{3}\right) \\
\text { Solvent } \\
\text { Cyclohexane, aliphatic } \mathrm{H} \text { atom } 1 \text { alpha } \mathrm{N}-\text { form methane } \\
\text { Aliphatic-H atom (multiplet) } \\
3 \mathrm{H} \text { atom on the methyl group of para-methoxy benzoic acid }\end{array}$ \\
\hline${ }^{13} \mathrm{C}$ & $\begin{array}{l}173.6 \\
128.2 \\
50.0 \\
139.3 \\
23.9,30.65\end{array}$ & $\begin{array}{l}173.8 \\
130.7,112.5 \\
50.3,30 \\
129.6 \\
24.0,30.7 \\
54.37\end{array}$ & $\begin{array}{l}\text { Carbonyl, } \mathrm{C} \text { atom in acid } \\
\mathrm{C} \text { atom in the benzene ring } \\
\mathrm{C} \text { atom in the cyclohexane } \\
\text { Benzoate, } \mathrm{C} \text { atom in the benzene ring } \\
\text { Alpha, beta, gamma } \mathrm{C} \text { from aliphatic, gamma } \mathrm{N} \text { from aliphatic }(\mathrm{C}-\mathrm{C}) \\
\text { Methyl group }\end{array}$ \\
\hline
\end{tabular}

fluorescence emission spectra for BCT and C4MB crystal samples were recorded in the range from 400 to $600 \mathrm{~nm}$ at excitation wavelength 400 and $520 \mathrm{~nm}$, respectively. The fluorescence spectra of both crystals are given in figure 7 . The emission was assigned to the electronic transition from $\pi^{*}$ antibonding molecular orbital to $\pi$ bonding molecular orbital of both crystals. The higher intensity ratio indicates purity and perfect crystallinity of the title compounds. Hence, both crystals are suitable for optoelectronic laser devices. 

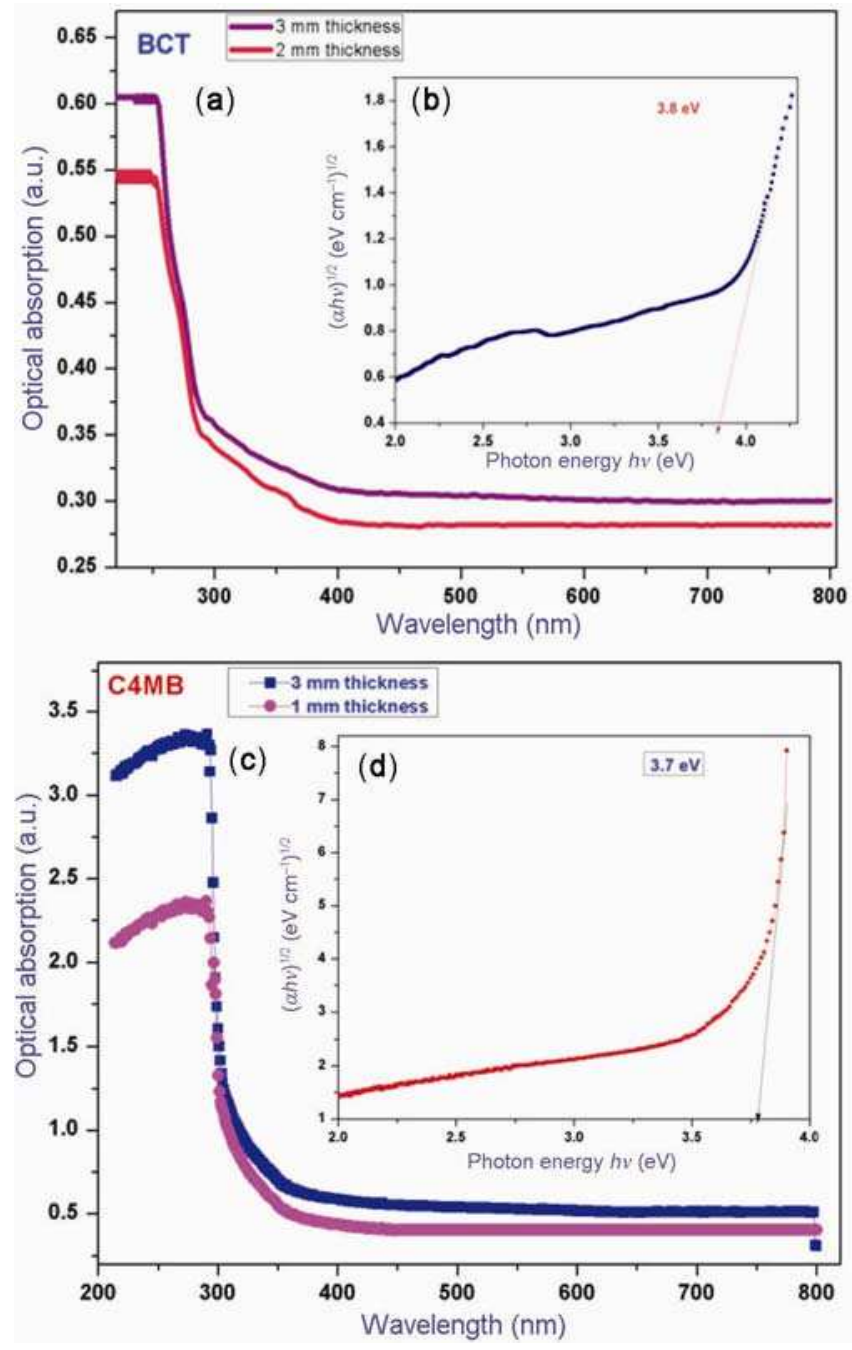

Figure 6. (a, b) Plot of UV-visible absorption spectrum and bandgap of BCT crystal and (c, d) C4MB crystal.

\subsection{Hardness test}

Mechanical stability of organic single crystal is very important for device fabrication. Vickers microhardness tests were performed on the grown crystals with flat and smooth faces for applied loads 5, 10, 25 and $50 \mathrm{~g}$. The indentation time was kept constant as $5 \mathrm{~s}$ for each load. Vickers microhardness $H_{\mathrm{V}}$ was computed using the relation $H_{\mathrm{V}}=1.8544 P / d^{2} \mathrm{~kg} \mathrm{~mm}^{-2}$, where $P$ is applied load in $\mathrm{kg}$ and $d$ is indentation diagonal length in $\mathrm{mm}$. A graph was plotted between hardness number $\left(H_{\mathrm{V}}\right)$ and applied load $(P)$ as shown in figure $8 \mathrm{a}$. The hardness of BCT and $\mathrm{C} 4 \mathrm{MB}$ crystals increases with increasing load, which indicates the reverse indentation size effect (RISE). Above $50 \mathrm{~g}$ crakes were observed owing to release of internal stresses generated locally by indentation. The RISE occurs in crystals which undergo plastic deformation. The RISE can be caused in two ways (i) the relative predominance of nucleation and multiplication of dislocations

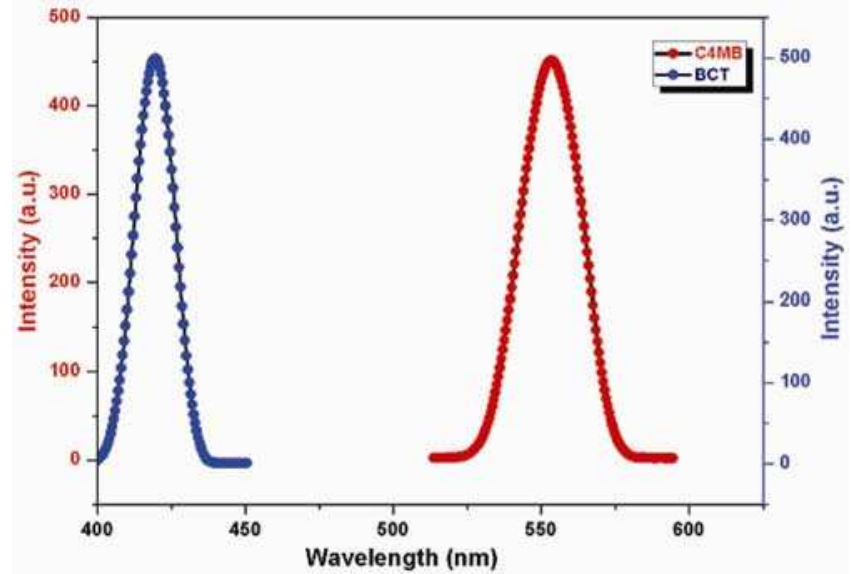

Figure 7. Fluorescence spectrum of $\mathrm{BCT}$ and $\mathrm{C} 4 \mathrm{MB}$.

and (ii) the relative predominance of activity either two sets of slip planes of a particular slip system or two slip systems below and above a particular load. ${ }^{20}$

Meyer's index number $(n)$ can be calculated from the Meyer's law

$$
\begin{aligned}
& P=k d^{n}, \\
& \log P=\log k+n \log d .
\end{aligned}
$$

From the careful observations, Onitsch ${ }^{21}$ and Hanneman ${ }^{22}$ pointed out that $n$ lies between 1 and 1.6 for moderately hard materials and it is more than 1.6 for soft materials. The slope of the graph plotted between $\log P v s . \log d$ (figure $8 b$ ) gives Meyer's index number $(n)$. The value of $n$ obtained for BCT is 2.6 and C4MB is 2.4. Hence both crystals belong to soft material category.

Elastic stiffness constant gives the idea of tightness of bonding between neighbouring atoms. ${ }^{23}$ The stiffness constant $\left(C_{11}\right)$ is calculated from Wooster's empirical relation $^{24}$ given by

$$
C_{11}=H_{\mathrm{V}}{ }^{7 / 4} \text {. }
$$

The variation of stiffness constant $\left(C_{11}\right)$ with various loads is shown in figure $8 \mathrm{c}$.

The yield strength $\left(\sigma_{\mathrm{y}}\right)$ was calculated from hardness values. The yield strength depends on Meyer's index number $n$. For $n>2, \sigma_{\mathrm{y}}$ can be calculated using the relation

$$
\sigma_{\mathrm{y}}=\frac{3-n}{2.9}\left(\frac{[12.5(n-2)]}{3-n}\right)^{n-2} H_{\mathrm{V}} .
$$

For $n<2$, the yield strength is calculated using the expression

$$
\sigma_{\mathrm{y}}=\frac{H_{\mathrm{V}}}{3} .
$$

From figure $8 \mathrm{~d}$, it is observed that yield strength increases with increasing load. 

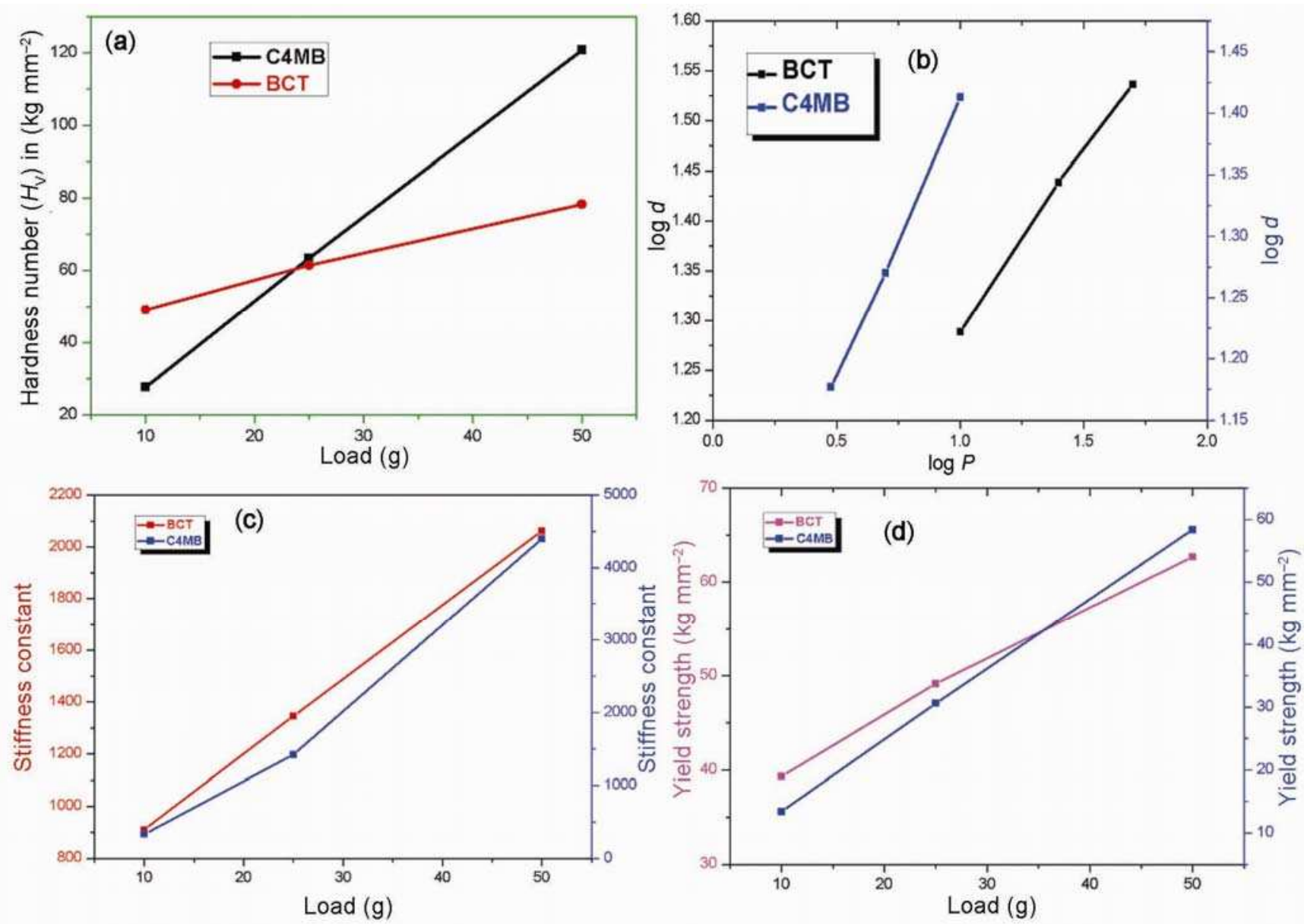

Figure 8. (a) Vickers microhardness test curve for BCT and C4MB. (b) plot of $\log P v s$. $\log d$ for BCT and C4MB crystals. (c) Variation of stiffness constant with load of BCT and C4MB crystals and (d) Variation of yield strength with load of BCT and C4MB crystals.
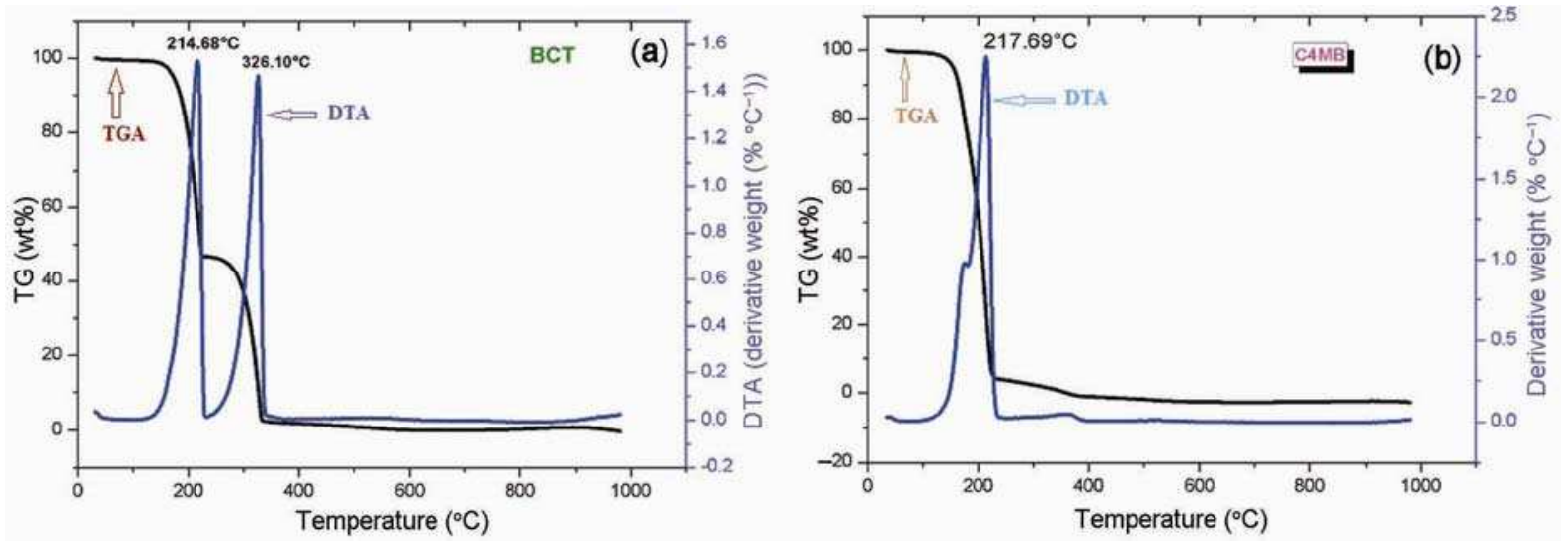

Figure 9. Thermal analysis curves of (a) BCT and (b) C4MB.

\subsection{Thermal analysis}

Thermograms provide information about decomposition patterns and weight loss of the materials. Differential thermal analysis (DTA) curve gives information regarding the phase transformations, water of crystallization and melting point of the compound. ${ }^{25}$
TG/DTA curves of BCT and C4MB are shown in figure 9. In DTA curve both the compounds exhibit sharp exothermic peak at 214.6 and $217.6^{\circ} \mathrm{C}$ which are attributed to meting point of the $\mathrm{BCT}$ and $\mathrm{C} 4 \mathrm{MB}$, respectively. The second exothermic peak in DTA curve at $326^{\circ} \mathrm{C}$ indicates that the material is fully decomposed. The sharpness of exothermic peaks infers the good degree of 
Table 4. SHG output for BCT and C4MB.

\begin{tabular}{lccl}
\hline Input energy & $\mathrm{KDP}$ & $\mathrm{BCT}$ & $\mathrm{C} 4 \mathrm{MB}$ \\
\hline $680 \mathrm{~mJ}$ & $2.5 \mathrm{mV}$ & $2.2 \mathrm{mV}$ & $3.8 \mathrm{mV}$ \\
\hline
\end{tabular}

crystallinity of grown samples. The DTA curve of BCT crystal has two exothermic peaks, which are due to two carboxylate ester that decomposed at two different temperatures, whereas for $\mathrm{C} 4 \mathrm{MB}$ crystal one carboxylate ester completely decomposed at $217^{\circ} \mathrm{C}$. From TGA curves, it is observed that $\mathrm{BCT}$ is thermally stable up to $189.65^{\circ} \mathrm{C}$ and $\mathrm{C} 4 \mathrm{MB}$ up to $154.26^{\circ} \mathrm{C}$. There is no phase transition till the title materials decompose.

\section{$3.8 \quad$ NLO studies}

The SHG conversion efficiency of the compound was measured by the Kurtz and Perry ${ }^{26}$ powder technique. The efficiency of the energy (frequency) conversion is confirmed by the emission of green light from the powder sample. Input power of laser is $680 \mathrm{~mJ}$ and pulse width of $8 \mathrm{~ns}$ and repetition rate of $10 \mathrm{~Hz}$. The input laser beam was passed through an IR reflector to the sample. Photodiode and oscilloscope were assembled to detect the light emitted by samples. The output power is measured as $2.5 \mathrm{mV}$ for potassium dihydrogen phosphate (KDP) crystal. For the same input, BCT and C4MB samples emitted the green light with the output power of 2.2 and $3.8 \mathrm{mV}$, respectively (table 4). It is inferred that the C4MB compound exhibits a reasonable SHG output, where methoxy $(-\mathrm{OMe})$ group substitutes in the para position of phenyl ring, when compared to BCT crystal which exhibits less SHG efficiency.

\section{Structural relationship}

Crystal structure of the both materials suggests the intermolecular charge transfer from the carboxyl hydrogen to the nitrogen atom of the bases through hydrogen bond interactions. The hydrogen bond conjugated path can induce large molecular dipole moment and molecular polarizability of the title compounds, which yield NLO efficiency. In the C4MB crystal, very week intramolecular hydrogen bonds between $\mathrm{C}-\mathrm{H}$ (methyl) groups as proton donors, and the $\mathrm{N}, \mathrm{O}$ atoms and the $\pi$ electrons of the aromatic ring as the proton acceptors promote the high SHG signal. And also, methyl groups substituted in para position of phenyl ring are non-planar, which predicts maximum conjugation of molecule with donor and acceptor groups. But in the case of BCT crystal, only the $\mathrm{N}-\mathrm{H}$... O intermolecular interaction takes place, which emphasize its lessor SHG efficiency than C4MB. The main reasons to get high $\mathrm{SHG}$ efficiency in $\mathrm{C} 4 \mathrm{MB}$ crystal is both inter- and intramolecular hydrogen bonds in the molecules. ${ }^{27}$ Hence C4MB crystalline powder exhibits high SHG efficiency compared to BCT compound.

\section{Conclusion}

BCT and C4MB crystals were grown by the slow evaporation solution technique for the present investigation. The unit cell parameters were confirmed by single-crystal XRD analysis. FT-IR spectrum clearly confirmed the presence of various functional groups present in both the crystals. NMR studies confirmed the placing of proton and carbon in the BCT and C4MB molecules. From UVvis spectral analysis, it is observed that crystals have good transparency in the entire visible region. Fluorescence spectrum shows the broad emission peaks at 422 and $558 \mathrm{~nm}$, respectively, for BCT and C4MB crystals. From the Vickers microhardness test, hardness number $\left(H_{\mathrm{V}}\right)$, yield strength $\left(\sigma_{\mathrm{y}}\right)$ and elastic stiffness constant $\left(C_{11}\right)$ were calculated. The Vickers microhardness studies show the RISE and both crystals are categorized under soft materials. The crystals are thermally stable up to 190 and $154^{\circ} \mathrm{C}$ for $\mathrm{BCT}$ and $\mathrm{C} 4 \mathrm{MB}$, respectively. Cyclohexylammonium p-methoxy benzoate molecule has a methyl group as proton donor, and the $\mathrm{N}, \mathrm{O}$ atoms and the $\pi$ electrons of the aromatic ring as the proton acceptors to induce SHG character. The Kurtz and Perry powder technique reveals the $\mathrm{C} 4 \mathrm{MB}$ crystalline powder exhibits high nonlinearity due to strong intermolecular hydrogen bond.

\section{References}

1. Nakanishi H, Matsuda H, Okada S and Kato M 1989 Adv. Mater. 197

2. Matsukawa T, Yoshimura M, Takahashi Y, Takemoto Y, Takeya K, Kawayama I, Okada S, Tonouchi M, Kitaoka Y, Mori Y and Sasaki T 2010 Jpn. J. Appl. Phys. 49075502

3. Shivachev B L, Kossev K, Dimowa L T, Yankov G, Petrov T, Nikolova R P and Petrova N 2013 J. Cryst. Growth 37641

4. Thomas Joseph Prakash J and Gnanaraj M S 2015 J. Spectrochem. Acta, Part A: Mol. Biomol. Spectrosc. 13539

5. Jha P C, Anusooya Pati Y and Ramasesha S 2005 Mol. Phys. 1031859

6. Ukachi T, Shigemoto T, Komatsu H and Sugiyama T 1993 J. Opt. Soc. Am. B $\mathbf{1 0} 1372$

7. Yang Z, Aravazhi S, Schneider A, Seiler P, Jazbinsek M and Gunter P 2005 Adv. Funct. Mater. 151072

8. Ravindra H J, John Kiran A, Dharmaprakash S M, Satheesh Rai N, Chandrasekharan K, Kalluraya B and Rotermund F 2008 J. Cryst. Growth 3104169

9. Zhao P S, Wang X, Jian F F, Zhang J L and Xiao H L 2010 J. Serb. Chem. Soc. $\mathbf{7 5} 459$

10. Suresh S 2013 Br. J. Appl. Sci. Technol. 3340

11. Patil P S, Bhumannavar V M, Bannur M S, Kulkarni H N and Bhagavannarayana G 2013 J. Cryst. Process. Technol. 3108

12. Tam W, Cheng L-T, Bierleinl J D, Cheng L K, Wang Y, Feiring A E, Meredith G R, Eaton D F, Calabrese J C and Rikken G L J A 1991 ACS Symp. Series 455158 
13. Han M T 2012 Acta Crystallogr. 681579

14. Wei B 2011 Acta Crystallogr. 672185

15. Stuart B H 2005 Infrared spectroscopy: fundamentals and applications, analytical technique in the science, doi: 10.1002/0470011149

16. Sajan D, Hubert Joe I and Jayakumar V S 2006 J. Phys.: Conf. Ser. 28123

17. Sankar R, Raghavan C M, Balaji M, Kumar R M and Jayavel R 2007 Cryst. Growth Des. 7348

18. Josepha L, Sajana D, Shettigar V, Chaitanya K, Tom Sundius N M and Nemec I 2013 Mater. Chem. Phys. 141 248
19. Waghmare V G, Kariya K P and Paliwal L J 2011 Mater. Sci. Eng. B 1485

20. Sangwal K 2000 Mater. Chem. Phys. 63145

21. Onitsch E M 1947 Mikroskopie 2131

22. Hanneman M 1941 Metall. Manch 23135

23. Khalil S M 2012 AIP Adv. 2042183

24. Wooster W A 1953 Rep. Prog. Phys. 1616

25. Meng F Q, Lu M K, Yang Z H and Zeng H 1998 Mater. Lett. 33265

26. Kurtz S K and Perry T T 1968 J. Appl. Phys. 393798

27. Rappoport Z 2007 The chemistry of aniline (England: Wiley) p 1807 